\title{
Simulation of Substructure Shaking Table Test Based on Multi-Parameter Controlling AMD Device
}

\author{
Jin-Bao Jla , Peng-Li CONG ${ }^{b}$, Chen-Guang WANGc \\ (Beijing Key Lab of Earthquake Engineering and Structural Retrofit , Beijing University of \\ Technology, Beijing 100124,China) \\ ajinbao@bjut.edu.cn,bcongpengli@outlook.com
}

\begin{abstract}
Keywords: shaking table; substructure test; Active Mass Driver; Multi-Parameter Control Abstract. To overcome the loading and control difficulty in the traditional substructure shaking table tests, an experimental technology loading the experimental substructure with active mass driver device (Abbreviated as AMD) under multi-parameter control (Abbreviated as MPC) was presented and analyzed in this paper. The numerical model of the test system was built and the performance of the MPC- AMD loading method was verified thourgh numberical simulation. The result shown that this method could improve the control performance significantly and has many advantages for future tests.
\end{abstract}

\section{Introduction}

In order to overcome the limitations of large scale structural test in conventional shaking table test, a real-time substructure test method based on shaking table is presented ${ }^{[1-5]}$. The real-time substructure test means that the entire model is divided into numerical substructure and experimental substructure according to the needs. The part of the structure that will not be destroyed or clearly mechanical behavior will be the numerical substructure, and the rest of the structure is tested as experimental substructure ${ }^{[6-12]}$. The interface force between the experimental substructure and the numerical substructure was provided by an actuator set on reaction wall. Restricted by laboratory space and installation conditions, this test method cannot be achieved if the reaction wall cannot be installed near the shaking table. Meantime, the displacement of the actuator installed on the reaction wall is relative to the static ground, so this kind of substructure test requires a larger stroke of the actuator. In order to solve these problems, this paper proposes an AMD device with Multi-Parameter Control to load the experimental substructure, and can improve the control precision of various physical quantities at the same time. Numerical simulation results verify the effectiveness and superiority of the Multi-Parameter Controlling AMD technique for substructure shaking table test.

\section{Theoretical Analysis}

\section{Substructure Split.}

For the convenience of research, the Benchmark model used in the experiment usually adopts a simple shear model. Therefore, this paper takes the $n$-story shear frame structure as the research object, considering that the lower stories are easily damaged in the earthquake, assuming the lower $i$-stories of the building are the experimental substructure and the upper $(n-i)$ stories are linear numerical substructure. During the test, the dynamic effects of the numerical substructure on the experimental substructure are exerted through the AMD device. 
The expression of the motion differential equation of the entire structure can be expressed as:

$$
M+C X^{\alpha}+K X=-M H \&
$$

In the formula, $M, C$ and $K$ represent the mass, damping and stiffness matrix of the entire structure model respectively; $X$ are acceleration, speed and displacement vector with respect to the top of shaking table; $H$ is the unit vector, and indicates input ground motion acceleration. Considering the 1 to $i$-th floor as the experimental substructure, the differential equation of the experimental substructure can be expressed as:

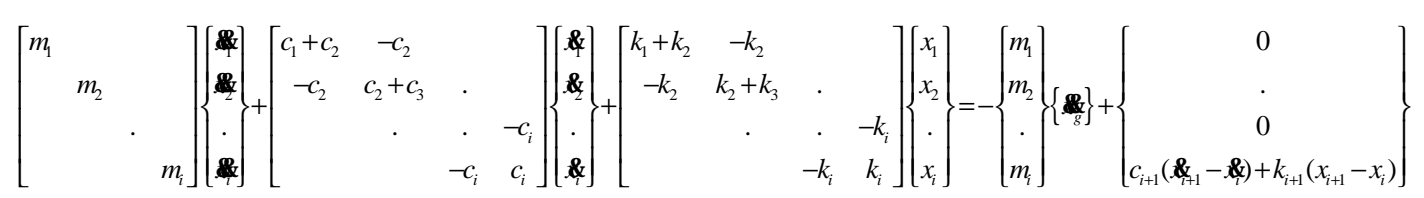

Considering the numerical substructure from $i+1$ to $n$-th floor, the differential equation of the numerical substructure can be expressed as:

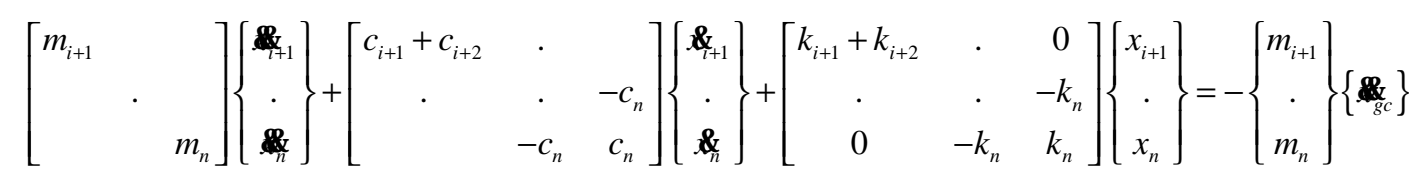

Where $m_{i}, c_{i}$, and $k_{i}, i=1,2 \mathrm{~L} n$ denote the concentration mass, interlayer damping coefficient, and interlayer stiffness for each story; Where $x_{e}$, and $e=1,2 \mathrm{~L} i$ are the displacement, velocity and acceleration of the corresponding story with respect to the shaking table top; Where $x_{c}$, and $c=i+1,2 \mathrm{~L} n$ are the displacement, velocity, and acceleration of the corresponding story relative to the top floor of the experimental substructure; Where reprents the numerical substructure input acceleration.

Experimental substructure and numerical substructure realize the transfer of physical quantities through the interaction force of the artificial dissection interface. The horizontal force at the top of the experimental substructure is the base shear of the numerical substructure, and the dynamic input of the numerical substructure is the absolute acceleration of the top floor of the experimental substructure.

\section{Modeling of AMD Loading Device}

The AMD loading device mentioned in this paper basically includes four parts: actuator, mass block, bearing and vertical support. Referring to analysis method of the shaking table system, an AMD loading device model is established. For the AMD device, the force principle is similar to the traditional shaking table. The difference is that the foundation of AMD is connected to the experimental substructure. When modeling the mass block and actuator in the AMD loading device, it is assumed that the load property is a pure inertia load in the hydraulic transmission and the mass block is considered as a rigid body. The open-loop transfer function of the AMD device is shown in Equation (4). The displacement or acceleration of the input AMD device is relative to the top floor of the experimental substructure, and the relative acceleration of mass block output must satisfy the Equation (5).

$$
\begin{gathered}
\frac{x}{E}=\frac{k_{q} A_{p}}{m_{k} s^{2}\left(\frac{V_{t}}{4 \beta_{e}} s+K_{c}+C_{c}\right)+A_{p}^{2} s} \\
\left(\frac{\mathrm{w}}{\mathrm{w}}\right) m_{k}=f_{m}
\end{gathered}
$$


Where $Q_{L}$ represents load flow; $k_{q}$ is flow gain of slid valve near static operation point; $E$ is control error signal; $K_{c}$ is flow pressure parameter of slid valve near static operation point; $p_{L}$ is load pressure; $A_{P}$ is effective bearing area of valve; $m_{k}$ is the valve of mass block; $x_{m}$ is displacement of the mass block; $V_{t}$ is gross capacity of two hydraulic cylinder chamber; Where $\beta_{e}$ represents oil elastic modulus; and $C_{c}$ is gross leakage coefficient of hydraulic cylinder; and $f_{m}$ respectively represent relative acceleration and inertial force of the mass block.

Combined with the mature application of jerk in other fields, this paper introduces the Multi-Parameter Control(MPC) by adding jerk link, which based on the Three Variable Control(TVC) of the traditional control method of the shaking table. The jerk can be used as an evaluation index for the instantaneous change of the reciprocating motion of the actuator.

\section{Modeling of Simulation System}

\section{Selection of Structural Model}

The 5-story shear frame structure is chosen as the research object, the bottom two stories make up experimental substructure, and the upper three stories are the numerical substructure. The natural frequencies of the structure are $1.98 \mathrm{~Hz}, 6.26 \mathrm{~Hz}, 11.23 \mathrm{~Hz}$, and other parameters are shown in Table 1. Without considering the nonlinearity of the experimental substructure, the scale model of the selected experimental substructure will be tested at Beijing University of Technology. Referring to the 1.1 section, the kinematic equations of the experimental substructure and the numerical substructure are transformed into state-space equations, and the simulation is carried out by using Simulink.

Table 1 The parameters of structure model

\begin{tabular}{cc}
\hline First story mass & $582[\mathrm{~kg}]$ \\
Bottom second to & $605[\mathrm{~kg}]$ \\
fourth story mass & $462[\mathrm{~kg}]$ \\
Top mass & $3129.9[\mathrm{kN} / \mathrm{m}]$ \\
\hline
\end{tabular}

\section{The Determination of the Parameters of the AMD Device}

According to the calculation value of interlayer shear force under the action of Northridge seismic wave with the peak acceleration of $0.2 \mathrm{~g}$ and the mass distribution of each story, the design parameters of AMD are determined as shown in Table 2. Seven seismic waves, such as El Centro, are chosen according to the site type as the input seismic waves of the experimental substructure. Considering their generality, the amplitude of the seismic waves is adjusted to $0.2 \mathrm{~g}$.

Table 2 Design parameters of the AMD device

\begin{tabular}{cc}
\hline Stroke limit & $\pm 0.10[\mathrm{~m}]$ \\
Work pressure & $21[\mathrm{Mpa}]$ \\
Hydraulic cylinder effective area & $1.9 \times 10^{-3}\left[\mathrm{~m}^{2}\right]$ \\
Hydraulic cylinder effective volume & $3.8 \times 10^{-4}\left[\mathrm{~m}^{3}\right]$ \\
Load mass & $95[\mathrm{~kg}]$ \\
\hline
\end{tabular}


Under the MPC, according to Figure 1 and the parameters in Table 1 and Table 2, the optimal control parameters are selected by the control system analysis, time and frequency domain correction, and the simulation is carried out by Simulink.

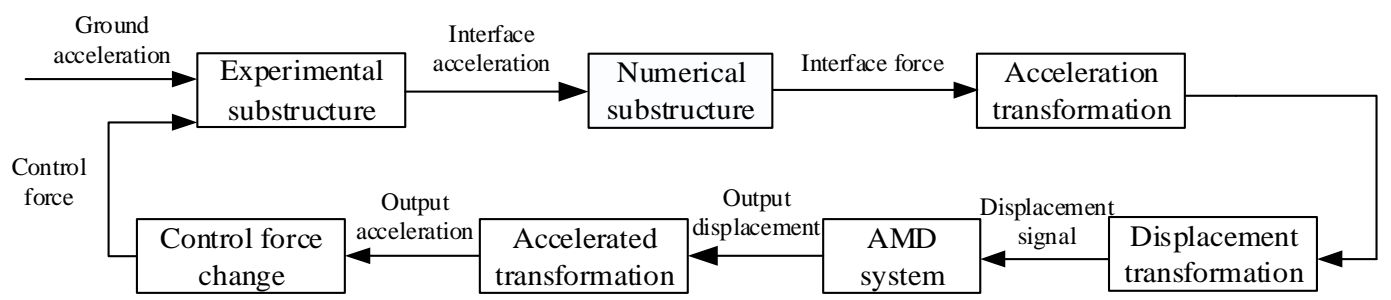

Fig. 1 The flow chart of substructure test simulation

\section{Comparison and Analysis of Simulation Results}

The seismic response of the entire structure and the structural response of the substructure shaking table test based MPC controlling AMD are calculated by numerical simulation. The interface force between experimental substructure and numerical substructure, the bottom displacement and bottom acceleration of experimental substructure are taken as evaluation indexes. Formula (6) is used to calculate the root mean square error of the dynamic response of the entire structure and substructure under the MPC, and the results are shown in Table 3.

$$
R M=\sqrt{\frac{\sum_{i=1}^{n}\left(x_{a b s}-x_{\text {mod } e l}\right)^{2}}{n}}
$$

In the formula, $R M$ represents the root mean square error; $x_{a b s}$ represents the seismic response of the entire structure, and $x_{\text {model }}$ represents the seismic response of the substructure shaking table test based on MPC method; $n$ indicates the number of time steps, and $i$ is the time step index.

Table 3 Comparison of calculative results of multi-parameter control

\begin{tabular}{|c|c|c|c|c|c|c|c|c|c|}
\hline & \multicolumn{3}{|c|}{$\begin{array}{l}\text { Interface force } \\
\qquad[\mathrm{N}]\end{array}$} & \multicolumn{3}{|c|}{$\begin{array}{c}\text { Displacement } \\
{[\mathrm{m}]}\end{array}$} & \multicolumn{3}{|c|}{$\begin{array}{c}\text { Acceleration } \\
\qquad\left[\mathrm{m} / \mathrm{s}^{2}\right]\end{array}$} \\
\hline Seismic wave & $\mathrm{RM}\left(10^{2}\right)$ & $\operatorname{PK}\left(10^{3}\right)$ & $\mathrm{RM} / \mathrm{PK}$ & $\mathrm{RM}\left(10^{-4}\right)$ & $\operatorname{PK}\left(10^{-3}\right)$ & $\mathrm{RM} / \mathrm{PK}$ & $\mathrm{RM}$ & PK & $\mathrm{RM} / \mathrm{PK}$ \\
\hline Chichi,1999 & 1.369 & 8.986 & $1.5 \%$ & 0.586 & 3.386 & $1.7 \%$ & 0.027 & 3.680 & $0.7 \%$ \\
\hline Kobe, 1995 & 4.109 & 10.580 & $3.9 \%$ & 1.758 & 4.424 & $4.0 \%$ & 0.080 & 2.575 & $3.1 \%$ \\
\hline Chalfant Valley, 1986 & 1.429 & 6.165 & $2.3 \%$ & 0.611 & 2.373 & $2.6 \%$ & 0.028 & 2.376 & $1.2 \%$ \\
\hline ElCentro, 1940 & 2.724 & 10.372 & $2.6 \%$ & 1.163 & 3.977 & $2.9 \%$ & 0.053 & 3.239 & $1.6 \%$ \\
\hline Northridge, 1994 & 4.754 & 11.820 & 4. $0 \%$ & 2.028 & 5.219 & $3.9 \%$ & 0.092 & 2.923 & $3.1 \%$ \\
\hline Taft,1952 & 2.793 & 9.411 & $3.0 \%$ & 1.188 & 3.835 & $3.1 \%$ & 0.053 & 3.756 & $1.4 \%$ \\
\hline Tianjin,1976 & 2.873 & 11.460 & $2.5 \%$ & 1.224 & 4.889 & $2.5 \%$ & 0.055 & 2.849 & $1.9 \%$ \\
\hline
\end{tabular}

NOTE:In the table, PK represents the peak value of the entire structure corresponding index.

According to the Table 3, the maximum ratios of the root mean square error of interface force, bottom displacement and bottom acceleration of the experimental substructure to their peaks are $4.0 \%, 4.0 \%$, and $3.1 . \%$. The average errors are $2.8 \%, 3.0 \%$, and $1.9 \%$, respectively. 


\section{Conclusion}

The theoretical analysis and numerical simulation show that the Multi-Parameter Controlling AMD device is used as the loading method of the substructure shaking table test,which has many advantages, such as no reaction wall, high control precision, advanced technology and easy implementation. The comparison analysis shows that the MPC has a better control precision than the displacement control on each dynamic response index, and can guarantee the test effect of the substructure shaking table test. The research work of this paper can provide a reference for the design of the loading scheme and the control algorithm for the substructure shaking table test, and provide a feasible test and research method for the study of the earthquake resistance.

\section{Acknowledgements}

This work was financially supported by The National Natural Science Foundation of China(General Program,Grant No. 51278013,51578024).

\section{References}

[1] Ghaboussi J, Yun G, Hashash Y. A novel predictor-corrector algorithm for sub-structure pseudo-dynamic testing.Journal of Earthquake Engineering and Structural Dynamics 2006; 35:453-476.

[2] Elkhoraibi T, Mosalam KM. Towards error-free hybrid simulation using mixed variables. Journal of Earthquake Engineering and Structural Dynamics 2007; 36:1497-1522.

[3] Li Yushun, Shan Wei, Li Junhua. Study on substructure pseudo-dynamic test[J]. China Civil Engineering Journal,2010(3):119-123.

[4] GUI Yao, CHI Fudong, WANG Jinting,et al. Advancements in real-time dynamic hybrid testing method[J]. Journal of Hydroelectric Engineering, 2012,31(6): 198-207.

[5] Ji, X., et al., A substructure shaking table test for reproduction of earthquake responses of high-rise buildings. EARTHQUAKE ENGINEERING \& STRUCTURAL DYNAMICS, 2009. 38(12): p. 1381-1399.

[6] Saouma V, Haussmann G, Kang D, et al. Real-Time Hybrid Simulation of a Nonductile Reinforced Concrete Frame[J]. Journal of structural engineering. 2014, 140(2).

[7] Wang Q, Wang J T, Jin F, et al. Real-time dynamic hybrid testing for soil-structure interaction analysis[J]. Rock \& Soil Mechanics, 2010, 31(12):1690-1702.

[8] Shao X, Reinhorn A M, Sivaselvan M V. Real-Time Hybrid Simulation Using Shake Tables and Dynamic Actuators[J]. Journal of Structural Engineering, 2015, 137(7):748-760.

[9] Gao X, Castaneda N, Dyke S J. Real time hybrid simulation: from dynamic system, motion control to experimental error[J]. Earthquake Engineering \& Structural Dynamics, 2013, 42(6):815-832.

[10]Darby A P, Blakeborough A, Williams M S. Real-Time Substructure Tests Using Hydraulic Actuator[J]. Journal of Engineering Mechanics, 1999, 125(10):1133-1139.

[11]Lee S K, Park E C, Min K W, et al. Real-time substructuring technique for the shaking table test of upper substructures[J]. Engineering Structures, 2007, 29(9):2219-2232. 
[12] Nakata, N. and M. Stehman, Substructure shake table test method using a controlled mass: formulation and numerical simulation. EARTHQUAKE ENGINEERING \& STRUCTURAL DYNAMICS, 2012. 41(14): p. 1977-1988.. 